\title{
The epidemiological aspects of tuberculosis in Hamadan Province during 2005-11
}

\section{Salman Khazaei ${ }^{1}$, Ghodratollah Roshanaei ${ }^{1}$, Mohammad Saatchi ${ }^{1}$, Shahab Rezaeian ${ }^{2, \star}$, Ali Zahiri ${ }^{3}$, Seyyed Jalal Bathaei ${ }^{3}$}

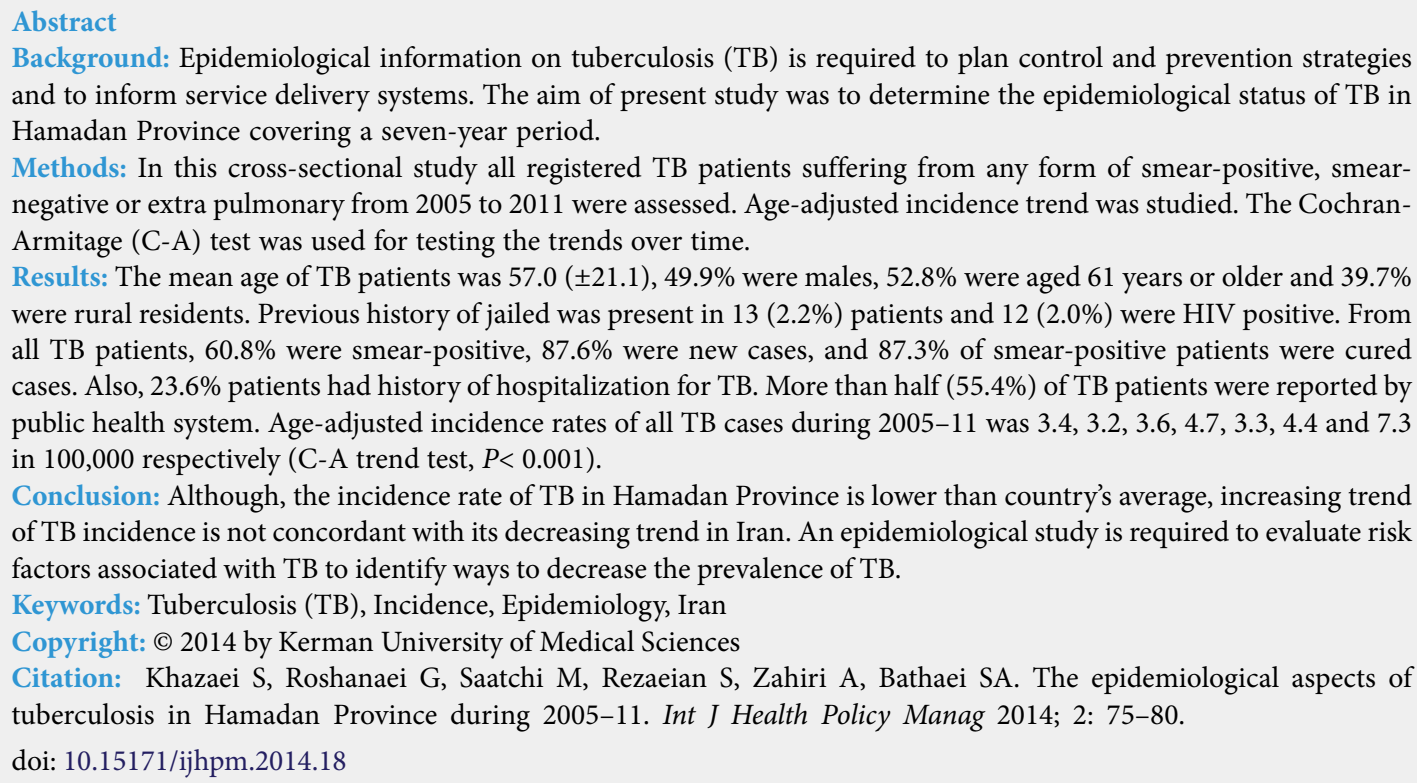
and to inform service delivery systems. The aim of present study was to determine the epidemiological status of TB in Hamadan Province covering a seven-year period.

Methods: In this cross-sectional study all registered TB patients suffering from any form of smear-positive, smearnegative or extra pulmonary from 2005 to 2011 were assessed. Age-adjusted incidence trend was studied. The CochranArmitage (C-A) test was used for testing the trends over time.

Results: The mean age of TB patients was $57.0( \pm 21.1), 49.9 \%$ were males, $52.8 \%$ were aged 61 years or older and $39.7 \%$ were rural residents. Previous history of jailed was present in $13(2.2 \%)$ patients and 12 (2.0\%) were HIV positive. From all TB patients, $60.8 \%$ were smear-positive, $87.6 \%$ were new cases, and $87.3 \%$ of smear-positive patients were cured cases. Also, 23.6\% patients had history of hospitalization for TB. More than half (55.4\%) of TB patients were reported by public health system. Age-adjusted incidence rates of all TB cases during 2005-11 was 3.4, 3.2, 3.6, 4.7, 3.3, 4.4 and 7.3 in 100,000 respectively (C-A trend test, $P<0.001$ ).

Conclusion: Although, the incidence rate of TB in Hamadan Province is lower than country's average, increasing trend of TB incidence is not concordant with its decreasing trend in Iran. An epidemiological study is required to evaluate risk factors associated with TB to identify ways to decrease the prevalence of TB.

Keywords: Tuberculosis (TB), Incidence, Epidemiology, Iran

Copyright: (C) 2014 by Kerman University of Medical Sciences

Citation: Khazaei S, Roshanaei G, Saatchi M, Rezaeian S, Zahiri A, Bathaei SA. The epidemiological aspects of tuberculosis in Hamadan Province during 2005-11. Int J Health Policy Manag 2014; 2: 75-80.

doi: $10.15171 /$ ijhpm.2014.18

Article History:

Received: 7 January 2014

Accepted: 22 February 2014

ePublished: 25 February 2014

*Correspondence to:

Shahab Rezaeian

Email: shahab_fs@yahoo.com

\section{Background}

Tuberculosis (TB) is considered as one of the major public health problems in developing countries, with an estimated 8.7 million new cases worldwide annually (1). In 2012, the incidence rate of TB was 14.4 per 100000 people in Iran (2). Out of 10987 TB registered cases 5386 cases, (49\%) had smear-positive pulmonary TB (2). The TB case detection rate in Iran was also below the global TB control target of $84 \%$ (3). Spreading of TB is accompanied by several epidemiological factors, notably the HIV/AIDS epidemic, low socio-economic status, overcrowding and malnutrition $(1,4)$.

Among the 22 countries that, together, account for $80 \%$ of all TB cases worldwide, Asian countries such as Afghanistan and Pakistan, the neighbor countries of Iran, are heavily affected by TB (5). This issue intensifies the problem of TB prevention in Iran.

Several studies have been conducted to investigate pulmonary TB and its different aspects. The current evidence suggests that numerous factors have effect on pulmonary TB such as drug resistance pattern, diagnosis delay, pattern of reported TB cases (6-8). With regards to demographic factors which include ethnicity and gender; for example, a study conducted in southern Iran reported that Afghan immigrants were at high risk for TB infected and women were also more affected (9). It is not possible to conduct a suitable program without sound evidence on epidemiology status of TB disease. Epidemiological information on TB is required to plan control and prevention strategies and to inform service delivery systems. Assessment of the epidemiological indices within a specific time period can also help planners to focus on the main problems of a community and to assess the efficacy of preventive programs. Given the reasons provided, the aim of present study was to determine the epidemiological status of TB in Hamadan Province covering a seven-year period.

\section{Methods}

This cross-sectional study was conducted in Hamadan Province, western Iran, in 2012. The total area of Hamadan Province is $19546 \mathrm{Km}^{2}$, with a population of over 1.7 million (2006 population census).

In this survey all registered TB patients suffering from any form of smear-positive, smear-negative or extra pulmonary from 2005 to 2011 (seven years) in all parts of Hamadan Province were assessed. TB cases were defined according to World Health Organisation (WHO) and Iran's national TB guideline (10). The Afghan immigrants, patients with wrong diagnosis and nonnative born citizen patients were excluded from the study. The available data were extracted from the National TB Program (NTP) using a checklist of items including demographic characteristics of the TB patients such as gender, age, time of diagnosis, source of reporting (public health system, private health system, Social Security Organization, other), history of hospitalization for TB (yes, no, unknown), recent close contact with TB patient (yes, no, unknown), group classification (new 
case, relapse, other), result of treatment (cured, and other-including: death, treatment failure, transfer out and unknown), place of residence (urban and rural), history of jailed (yes, no, or no data), HIV status (positive, negative, or no data), and type of TB (positive, negative, extra pulmonary). These data were obtained at the time of diagnosis and recorded in the TB register software.

For data analysis we used descriptive statistics including frequency tables, measures of central value and measures of dispersion to describe the study variables. Age-adjusted trend and incidence of all TB cases, smear-positive and negative pulmonary TB were analyzed during 2005-11. The CochranArmitage (C-A) test was employed to test the trends over time. To adjust for age, direct age adjustment was done by applying the population from 2005 as reference population.

To determine the annual rate of percent change in TB incidence during 2005-11, we also used the following formula:

$\frac{\text { incidence rate of final year-incidence rate of initial year }}{\text { number of years }} \times 100$

The sources of TB reporting (five levels) with dichotomous variables were compared using the Chi-square test. In so doing, the level of "other" was excluded as 75\% of TB reported cased were unknown. All the data were analyzed by Stata 11 (StataCorp LP, College Station, TX, USA).

Results

Of 623 registered TB patients during 2005-11, 26 cases were excluded due to exclusion criteria (Figure 1). Thus, a total of 597 patients are presented in this study. Table 1 shows distribution of characteristics of registered TB patients between 2005 and 2011.

The mean age of TB patients was 57.0 ( $\mathrm{SD} \pm 21.1$ ), $49.9 \%$ were males (the male-to-female ratio was 1.00), 52.7\% were aged 61 years or older and $39.7 \%$ were rural. Previous history of jailed was present in $13(2.2 \%)$ patients and $12(2.0 \%)$ were HIV positive.

From all TB patients, $60.8 \%$ were smear-positive, $87.6 \%$ were new cases and $87.3 \%$ of smear-positive patients were cured cases. Also, $23.6 \%$ of patients had history of hospitalization for TB. More than half $(55.4 \%)$ of TB patients were reported by public health system (Table 2).

Age-adjusted incidence and trends of $\mathrm{TB}$ case-finding are presented in Table 3. Compared with case reporting in 2005, reporting during the study period was significantly higher, rising from 115 expected number of cases to 252, annual rate of change: $56 \%$, (C-A trend test, $P<0.001$ ), particularly for new pulmonary smear-negative cases. Age-adjusted incidence of all TB cases during 2005-11 was 3.4, 3.2, 3.6, 4.7, 3.3, 4.4 and 7.3 in 100,000 respectively (C-A trend test, $P<0.001$ ). The ageadjusted prevalence of TB cases increased from 4.1 in 100,000; in 2005 to 8.5 in 100,000; in 2011 (C-A test, $P<0.001$ ).

The majority of reported $\mathrm{TB}$ cases in private clinics were aged 61 or older $(54.0 \%)$ and female $(60.5 \%)$ compared with public outpatient services $(P=0.029)$. Of the 215 reported cases of TB by public hospitals, 111 cases $(51.6 \%)$ were male and 104 $(48.4 \%)$ were female. However, the number of reported TB

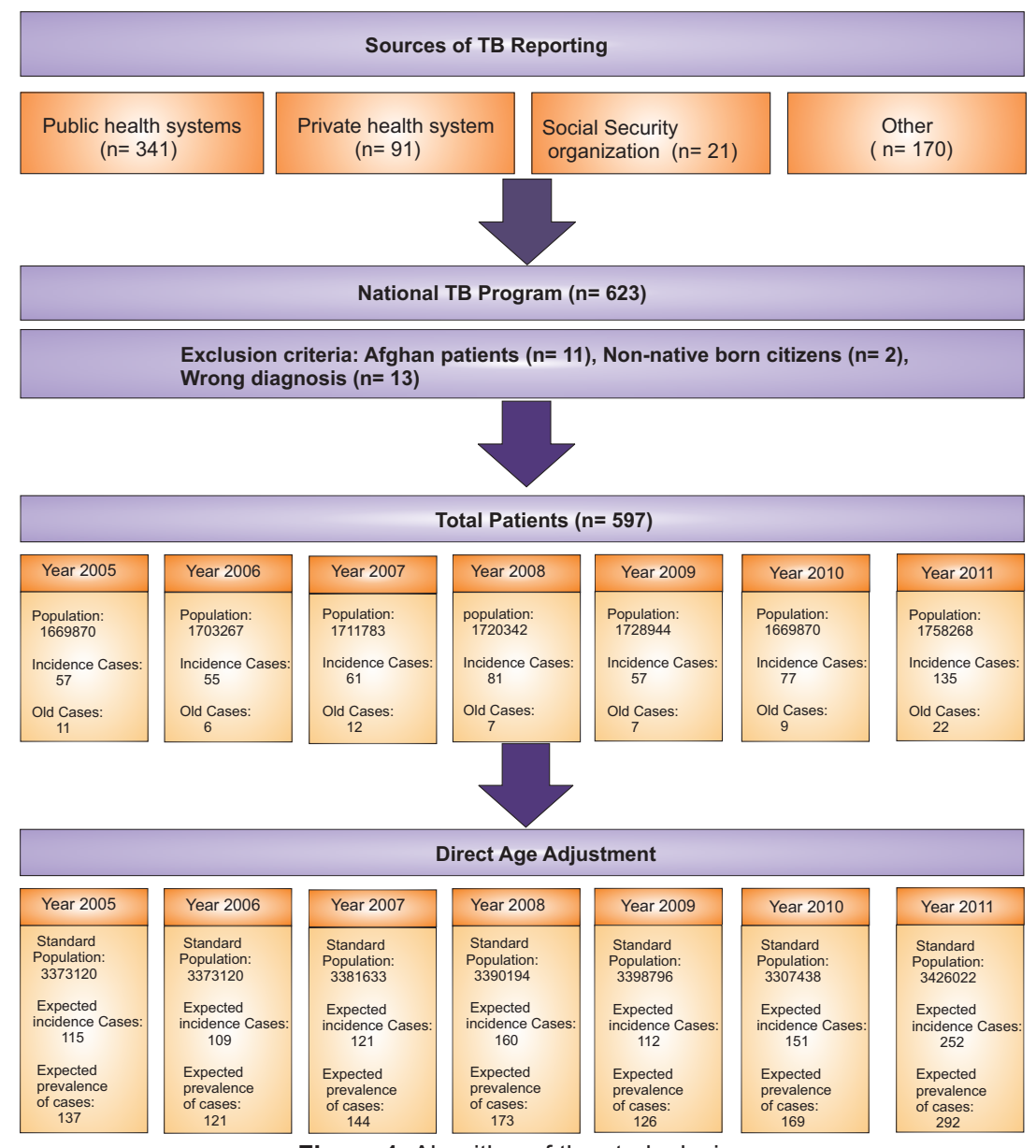

Figure 1. Algorithm of the study design 
Table 1. Characteristics of registered TB patients in Hamadan province, Iran, 2005-11

\begin{tabular}{|c|c|c|}
\hline Variables & Number & $\%$ \\
\hline \multicolumn{3}{|l|}{ Gender } \\
\hline Male & 298 & 49.9 \\
\hline Female & 299 & 50.1 \\
\hline \multicolumn{3}{|l|}{ Age group } \\
\hline 0-30 year & 93 & 15.6 \\
\hline $31-60$ year & 189 & 31.7 \\
\hline +61 year & 315 & 52.7 \\
\hline \multicolumn{3}{|l|}{ Place of residence } \\
\hline Urban & 360 & 60.3 \\
\hline Rural & 237 & 39.7 \\
\hline \multicolumn{3}{|l|}{ HIV status } \\
\hline Positive & 12 & 2.0 \\
\hline Negative & 32 & 5.4 \\
\hline Unknown & 553 & 92.6 \\
\hline \multicolumn{3}{|l|}{ Type of TB } \\
\hline Positive & 363 & 60.8 \\
\hline Negative & 113 & 18.9 \\
\hline Extra pulmonary & 121 & 20.3 \\
\hline \multicolumn{3}{|l|}{ Group Classification } \\
\hline New case & 523 & 87.6 \\
\hline Relapse & 25 & 4.2 \\
\hline Other & 49 & 8.2 \\
\hline \multicolumn{3}{|c|}{ Result of treatment (Smear-positive $=363$ ) } \\
\hline Cured & 317 & 87.3 \\
\hline Other $^{\mathrm{a}}$ & 46 & 12.7 \\
\hline \multicolumn{3}{|c|}{ Result of treatment (Smear-negative \& Extra pulmonary= 234) } \\
\hline Treatment completed & 165 & 70.5 \\
\hline Other & 69 & 29.5 \\
\hline \multicolumn{3}{|l|}{ History of jailed } \\
\hline Yes & 13 & 2.2 \\
\hline No & 552 & 97.8 \\
\hline \multicolumn{3}{|l|}{ History of hospitalization } \\
\hline Yes & 141 & 23.6 \\
\hline No & 329 & 55.1 \\
\hline Unknown & 127 & 21.3 \\
\hline
\end{tabular}

ather: Death, Treatment failure, Transfer out, and Unknown.

cases in males was more than females. But, this proportion was no significant $(P=0.103)$. In contrast, older TB cases were significantly higher in public hospitals than public outpatient services (70.2 vs. $29.8, P=0.03$; Table 4 ). Of the 116 TB reported cases by public outpatient services compared with public hospitals, 79 cases $(76.7 \%)$ were smear-negative TB and extra pulmonary and $23.3 \%$ were smear-positive $(P<0.001)$. In all, from $428 \mathrm{~TB}$ reported cases, $50.2 \%$ reported by public hospitals.

\section{Discussion}

The TB incidence is one of the most important surveillance indicators in public health. Although incidence and mortality of TB is declining globally except in Sub-Saharan Africa (11), but the results of present study revealed significant increase in the incidence rate of all TB classifications $(56 \%, P<0.001)$, especially in the incidence rate of new smear-negative pulmonary TB (30\%) in the $2005-11$ period. A similar study conducted by Salek et al. (12), to evaluate the alterations of TB epidemiologic indices in Golestan Province, demonstrated that only incidence of smear-negative pulmonary TB has changed significantly during the study period. According to Center for Iranian Disease Control and Prevention report, the incidence
Table 2. Comparison between investigated variables and gender using Chi-square test

\begin{tabular}{|c|c|c|c|}
\hline Variables & Male (\%) & Female (\%) & $\boldsymbol{P}$-value \\
\hline \multicolumn{4}{|l|}{ Age group } \\
\hline 0-30 year & $36(12.1)$ & $57(19.1)$ & \multirow{3}{*}{$<0.001$} \\
\hline 31-60 year & 118 (39.6) & $71(23.7)$ & \\
\hline +61 year & $144(48.3)$ & $171(57.2)$ & \\
\hline \multicolumn{4}{|l|}{ Place of residence } \\
\hline Urban & $189(63.4)$ & $171(57.2)$ & \multirow[t]{2}{*}{0.120} \\
\hline Rural & $109(36.6)$ & $128(42.8)$ & \\
\hline \multicolumn{4}{|l|}{ Type of TB } \\
\hline Positive & $180(60.4)$ & $183(61.2)$ & \multirow{3}{*}{0.414} \\
\hline Negative & $62(20.8)$ & $51(17.1)$ & \\
\hline Extra pulmonary & $56(18.8)$ & $65(21.7)$ & \\
\hline \multicolumn{4}{|l|}{ Group Classification } \\
\hline New case & 250 (83.9) & $273(91.3)$ & \multirow{3}{*}{0.016} \\
\hline Relapse & $18(6.0)$ & $7(2.3)$ & \\
\hline Other & $30(10.1)$ & $19(6.4)$ & \\
\hline \multicolumn{4}{|c|}{ Recent close contact with TB patient ${ }^{\mathrm{a}}$} \\
\hline Yes & $28(16.5)$ & $48(27.1)$ & \multirow[t]{2}{*}{0.018} \\
\hline No & $141(83.5)$ & 129 (72.9) & \\
\hline \multicolumn{4}{|c|}{ Result of treatment (Smear-positive $=363$ ) } \\
\hline Cured & 151 (83.9) & $166(90.7)$ & \multirow[t]{2}{*}{0.051} \\
\hline Other ${ }^{b}$ & $29(16.1)$ & $17(9.3)$ & \\
\hline \multicolumn{4}{|c|}{ Result of treatment (Smear-negative \& Extr a pulmonary= 234) } \\
\hline $\begin{array}{l}\text { Treatment } \\
\text { Completed }\end{array}$ & $79(66.9)$ & $86(74.1)$ & \multirow[t]{2}{*}{0.228} \\
\hline Other & $39(33.1)$ & $30(25.9)$ & \\
\hline \multicolumn{4}{|l|}{ Source of reporting } \\
\hline $\begin{array}{l}\text { Public health } \\
\text { System outpatient }\end{array}$ & $49(16.4)$ & $67(22.4)$ & \multirow{4}{*}{0.019} \\
\hline $\begin{array}{l}\text { Public health } \\
\text { System hospital }\end{array}$ & $111(37.3)$ & $104(34.8)$ & \\
\hline Private & $30(10.1)$ & $46(15.4)$ & \\
\hline Other & $108(36.2)$ & $82(27.4)$ & \\
\hline
\end{tabular}

aUnknown information on recent close contact with TB case has deleted= 251; ' Other: Death, Treatment failure, Transfer out, and Unknown.

rate of TB in Iran has shown a descending trend during past decades (142 in 100000 in 1964 to 14.4 in 100000 in 2012) (2). Nevertheless, the prevalence of HIV/AIDS in Iran has changed from low to concentrate phase and the estimated number of infected people with HIV by 2014 amounts to 106000 (13). Several previous studies have also reported TB/HIV coinfection; 30\% in Brazil (14), 15.8\% in western China (15), $42 \%$ in Southern Africa (16). All of these studies have revealed that HIV infection dramatically increases the incidence of TB (17). In addition, the rate of TB/HIV co-infection has been $2.4 \%$ in Iran in 2012 (2). We suggest that the prevalence of co-infection in the area under study is below the national average, and this might be associated with the low demand for HIV testing in the area, as a study performed in a neighbor province, Kurdistan revealed most participants $(68.9 \%)$ did not undergo HIV testing (18). As such, people and related organizations should pay more attention to the problem of co-infection. Results of a study conducted in Congo to assess the provision of HIV/TB co-infection services in health facilities revealed that $\mathrm{TB}$ care was more available than HIV care and TB/HIV co-infection rates among patients were unknown in $82 \%$ of the facilities (19). According to our findings, male to female ratio was 1.0 among TB patients, similar to the national report (11), while WHO has reported a male/female ratio of 1.9 for the case notification rate 
Table 3. Trends of TB case-finding in Hamadan Province, 2005-11

\begin{tabular}{|c|c|c|c|c|c|c|c|c|c|}
\hline \multirow{2}{*}{ TB classification } & \multicolumn{7}{|c|}{ Expected number TB cases reported } & \multirow{2}{*}{ \%increase $^{a}$} & \multirow{2}{*}{ C-A test } \\
\hline & 2005 & 2006 & 2007 & 2008 & 2009 & 2010 & 2011 & & \\
\hline Total population & 1669870 & 1703267 & 1711783 & 1720342 & 1728944 & 1737589 & 1758268 & - & - \\
\hline New TB cases (Total) & $115(3.4)$ & $109(3.2)$ & $121(3.6)$ & $160(4.7)$ & $112(3.3)$ & $151(4.4)$ & $252(7.3)$ & 56 & $<0.001$ \\
\hline New smear-positive & $73(2.2)$ & $73(2.2)$ & $89(2.6)$ & $114(3.4)$ & $81(2.4)$ & $94(2.8)$ & $89(2.6)$ & 6 & 0.126 \\
\hline New smear-negative & $10(0.3)$ & $10(0.3)$ & $8(0.2)$ & $18(0.5)$ & $20(0.6)$ & $43(1.3)$ & $81(2.4)$ & 30 & $<0.001$ \\
\hline New extra pulmonary & $32(1.0)$ & $26(0.8)$ & $24(0.7)$ & $28(0.8)$ & $12(0.3)$ & $14(0.4)$ & $82(2.4)$ & 20 & $<0.001$ \\
\hline Age-adjusted prevalence & $68(4.1)$ & $61(3.6)$ & $73(4.3)$ & $88(5.1)$ & $64(3.7)$ & $83(4.9)$ & $157(8.5)$ & 63 & 0.001 \\
\hline
\end{tabular}

Values in parentheses are age-adjusted incidence per 100000 people.

aannual rate of percent change in case finding during 2005-11.

Table 4. Comparison of age, gender and TB type in registered TB patients between different sources of TB reporting using Chi-square test

\begin{tabular}{|c|c|c|c|c|c|}
\hline \multirow{2}{*}{ Variable } & \multicolumn{4}{|c|}{ Source of reporting } & \multirow{2}{*}{ Total (\%) } \\
\hline & PHO (\%) & PHS (\%) & Private (\%) & Social security (\%) & \\
\hline \multicolumn{6}{|l|}{ Age } \\
\hline$<60$ year & $62(32.0)$ & $88(45.4)$ & $35(18.0)$ & $9(4.6)$ & $194(100)$ \\
\hline$>61$ year & $54(23.1)$ & $127(54.3)$ & $41(17.5)$ & $12(5.1)$ & $234(100)$ \\
\hline$P$-value & - & 0.029 & 0.316 & 0.371 & - \\
\hline \multicolumn{6}{|l|}{ Gender } \\
\hline Male & $49(24.1)$ & $111(54.7)$ & $30(14.8)$ & $13(6.4)$ & $203(100)$ \\
\hline Female & $67(29.8)$ & $104(46.2)$ & $46(20.4)$ & $8(3.6)$ & $225(100)$ \\
\hline$P$-value & - & 0.103 & 0.703 & 0.096 & - \\
\hline \multicolumn{6}{|l|}{ Type of TB } \\
\hline Smear-Positive & $27(15.3)$ & $113(63.8)$ & $26(14.7)$ & $11(6.2)$ & $177(100)$ \\
\hline Non-positive* & $89(35.5)$ & $102(40.6)$ & 50 (19.9) & $10(4.0)$ & $251(100)$ \\
\hline$P$-value & - & 0.001 & 0.097 & 0.006 & - \\
\hline Total & $116(27.1)$ & $215(50.2)$ & $76(17.8)$ & 21 (4.9) & $428(100)$ \\
\hline
\end{tabular}

Abbreviation: PHO; Public Health system Outpatient, PHS; Public Health System hospital, TB; Tuberculosis.

${ }^{*}$ Non-positive= smear-negative \& extra pulmonary. ${ }^{*} \mathrm{PHO}$ considered as reference group.

worldwide (11). In addition, a multi-centre case-control study conducted in three West African countries found a male/female ratio of 2.03 among patients with TB (20). The distinction between public health risks of infection and different lifestyles may account for this gender difference. For example, a recent study conducted by Atre et al. (21) to examine community perceptions of TB-related stigma showed that concealment of a disease such as TB happened more among females because of fear of losing social status, marital problems, or harmful reactions from the community.

In the present study, a large number of the TB/HIV co-infected patients were in the 31-60 year age group (91.7\%) with the mean age of $36.2( \pm 6.2)$ years and also were male. The fact that the highest occurrence was found in the 31-60 year age group suggests that the co-infected patients are individuals in the most productive phase of their life, which leads to economic losses and subsequently has social repercussions for patients, families, and society. These data are in agreement with those reported in the literature $(14,22)$ which confirm that TB/HIV co-infection is more common in males.

There was a statistically significant difference between gender and age groups $(P<0.001)$. Codlin et al. (23) showed that highest number of notified TB cases are in the 15-34 year age groups in both males and females, disproportionately more in females. There are a number of reasons justifying the high occurrence of TB in younger women compared to younger men; among others, adult women are more likely than adult men to have a close contact with TB patients because young women in this community mostly perform the nursing roles within the family. As shown in Table 2, the recent close contact with TB patients is more common in females than male $(P=0.018)$. Women are more likely than men to have strains in common with other patients (24).

The results of this study revealed that being smear-positive and age of 60 years or more were the most important predictive components of reporting source type which could be used for planning TB program. On the other hand, public hospitals were more likely than public outpatient services to report both smear-positive cases and patients aged 60 years or more. But, there was no significant difference between reporting system in terms of gender. In this study, the public hospitals (50.2\%), public outpatient services (27.1\%), and private sector (17.8\%) had the highest rate of reporting that is in concordant with other studies (6). Accordingly, the private system is one of the most effective sectors in TB program $(25,26)$, but their involvement in reporting smear-positive TB is extremely less than public health system (as shown in Table 4). In another study performed by Masjedi et al. (27) to determine TB detection in the private sector in Tehran, $87.3 \%$ of TB cases have been diagnosed by the private sector. In that study, authors concluded that the private sector plays a significant role in TB detection, but there is poor cooperation and communication between the private and public health systems. Although, health insurance system in Iran, and even in rural areas, has a high coverage, the rate of reporting from this sector was $4.9 \%$. As a result, involving the insurance organizations in TB program is necessary (6).

\section{Limitations}

This study was associated with a number of limitations. First, there probably is different sensitivity on diagnosis of extra 
pulmonary and smear-negative cases because of different physicians. Second, diagnosis of extra pulmonary cases was usually done based on clinical diagnosis instead of biopsy. Third, 22\% of source reporting (127 from 597 cases) was unknown. These issues may raise the possibility of information bias. Another limitation of this study was that the information of some variables such as HIV status and prison history of patients has not been directly investigated. Information about these factors was based on self-reported responses. Accordingly, self-report may again be a cause of potential information bias and underestimate real status of the variables. Notwithstanding, our study used a data with seven years period, the results may not be generalisable to the other areas.

\section{Conclusion}

Although, the incidence rate of TB in Hamadan Province is lower than country's average, increasing trend of TB incidence is not concordant with its decreasing trend in Iran. Upward trend in HIV prevalence and the importance of TB co-infection with HIV as an alarm should be considered. An epidemiological study is required to evaluate risk factors associated with TB to identify ways to decrease the prevalence of TB.

\section{Acknowledgements}

We would like to thank the TB coordinators and staffs of the Deputy of Health, Hamadan University of Medical Sciences for the authorization to conduct the study and for granting access to the data. This study was funded by the Vice-chancellor of Research and Technology, Hamadan University of Medical Sciences (Grant No. 9010143519).

\section{Ethical issues}

This study was approved by the local Human Subject Review board of Hamadan University of Medical Sciences.

\section{Competing interests}

The authors declare that they have no competing interests.

\section{Authors' contributions}

SK, GR, and MS contributed to conceiving and designing the study. The data was collected by SK, AZ, and SJB and was analysed and interpreted jointly by SR, SK, and MS. Both SR and SK contributed equally in writing the manuscript and all authors had an equal share in revising and approving the manuscript.

\section{Authors' affiliations}

${ }^{1}$ Department of Biostatistics and Epidemiology, School of Public Health, Hamadan University of Medical Sciences, Hamadan, Iran. ${ }^{2}$ Department of Epidemiology, School of Health, Shiraz University of Medical Sciences, Shiraz, Iran. ${ }^{3}$ Center for Disease Control \& Prevention, Deputy of Health Services, Hamadan University of Medical Sciences, Hamadan, Iran.

\section{References}

1. World Health Organization (WHO). Tuberculosis. Geneva: WHO; 2013.

2. Center for Disease Control and Prevention, Ministry of Health and Medical Education, Iran. Tuberculosis status [Internet]. 2012. Available from: http://www.cdc.hbi.ir/TB Situation in Iran.aspx.

3. World Health Organization (WHO). The global plan to stop TB 2011 2015: Transforming the fight towards elimination of tuberculosis. Geneva: WHO; 2010.

4. Harries AD, Dye C. Tuberculosis. Ann Trop Med Parasitol 2006; 5: 415-31.

5. World Health Organization (WHO). Global tuberculosis report 2012. Geneva: WHO; 2012.

6. Hassanzadeh J, Nasehi M, Rezaianzadeh A, Tabatabaee $\mathrm{H}$, Rajaeifard A, Ghaderi E. Pattern of reported tuberculosis cases in
Iran 2009-2010. Iran J Public Health 2013; 42: 72-8.

7. Marjani M, Baghaei P, Tabarsi P, Shamaei M, Mansouri D, Masjedi $\mathrm{MR}$, et al. Drug resistance pattern and outcome of treatment in recurrent episodes of tuberculosis. East Mediterr Health $J$ 2012; 18: 957-61.

8. Nasehi M, Hassanzadeh J, Rezaianzadeh A, Zeigami B, Tabatabaee $\mathrm{H}$, Ghaderi E. Diagnosis delay in smear positive tuberculosis patients. J Res Med Sci 2012; 17: 1001-4.

9. Moradi M, Arababadi MK, Hassanshahi G. Tuberculosis in the Afghan Immigrants in Kerman Province of Iran. $J$ Biol Sci 2008; 8: 1107-9.

10. World Health Organization (WHO). Treatment of Tuberculosis: Guidelines. Geneva: WHO; 2010.

11. World Health Organization (WHO). Global tuberculosis control: WHO report 2011. Geneva: WHO; 2011.

12. Salek S, Salek S, Emami H, Masjedi MR, Velayati AA. [Epidemiologic Status of Tuberculosis in Golestan Province]. Tanaffos 2008; 7: 638.

13. Haghdoost AA, Mostafavi E, Mirzazadeh A, Navadeh S, Feizzadeh A, Fahimfar N, et al. Modelling of HIVIAIDS in Iran up to 2014. JAHR 2011; 3: 231-9.

14. Muniz JN, Ruffino-Netto A, Villa TC, Yamamura M, Arcencio $\mathrm{R}$, Cardozo-Gonzales RI. Epidemiological aspects of human immunodeficiency virus/tuberculosis co-infection in Ribeirão Preto, Brazil from 1998 to 2003. J Bras Pneumol 2006; 32: 529-34.

15. Liu J, Lü B, Yan Y. Meta analysis on the co-infection between Mycobacterium tuberculosis and HIVIAIDS in China. Zhonghua Liu Xing Bing Xue Za Zhi 2013; 34: 85-90.

16. Chehab JC, Vilakazi-Nhlapo AK, Vranken P, Peters A, Klausner JD. Current Integration of Tuberculosis (TB) and HIV Services in South Africa, 2011. PLoS One 2013; 8: e57791.

17. Sonnenberg P, Glynn JR, Fielding K, Murray J, Godfrey-Faussett $P$, Shearer S. HIV and pulmonary tuberculosis: the impact goes beyond those infected with HIV. AIDS 2004; 18: 657-62.

18. Rezaeian S, Esmailnasab N. Social Determinants of Health Associated with Self-Reported HIV Testing among Women. Iran J Public Health 2013; 42: 436-42.

19. Kaboru BB, Ogwang BA, Namegabe EN, Mbasa N, Kabunga DK, Karafuli K. TB/HIV co-infection care in conflict-affected settings: a mapping of health facilities in the Goma area, Democratic Republic of Congo. Int J Health Policy Manag 2013; 1: 207-11.

20. Lienhardt C, Fielding K, Sillah JS, Bah B, Gustafson P, Warndorff $D$, et al. Investigation of the risk factors for tuberculosis: a casecontrol study in three countries in West Africa. Int $J$ Epidemiol 2005; 34: 914-23.

21. Atre S, Kudale A, Morankar S, Gosoniu D, Weiss MG. Gender and community views of stigma and tuberculosis in rural Maharashtra, India. Glob Public Health 2011; 6: 56-71.

22. Liberato IR, de Albuquerque Mde F, Campelo AR, de Melo HR. Characteristics of pulmonary tuberculosis in HIV seropositive and seronegative patients in a Northeastern region of Brazil. Rev Soc Bras Med Trop 2004; 37: 46-50.

23. Codlin AJ, Khowaja S, Chen Z, Rahbar MH, Qadeer E, Ara I, et al. Short report: gender differences in tuberculosis notification in Pakistan. Am J Trop Med Hyg 2011; 85: 514-7.

24. Glynn JR, Crampin AC, Yates MD, Traore H, Mwaungulu FD, Ngwira BM, et al. The importance of recent infection with Mycobacterium tuberculosis in an area with high HIV prevalence: a long-term molecular epidemiological study in Northern Malawi. $J$ Infect Dis 2005; 192: 480-7.

25. Dewan PK, Lal SS, Lonnroth K, Wares F, Uplekar M, Sahu S, et al. Improving tuberculosis control through public-private collaboration in India: literature review. BMJ 2006; 332: 574-8.

26. Sehgal S, Dewan PK, Chauhan LS, Sahu S, Wares F, Granich R. Public-private mix TB activities in Meerut, Uttar Pradesh, North India: delivering dots via collaboration with private providers and non-governmental organizations. Indian J Tuberc 2007; 54: 79-83.

27. Masjedi MR, Fadaizadeh L, Taghizadeh Asl A. Notification of patients with tuberculosis detected in the private sector, Tehran, Iran. Int J Tuberc Lung Dis 2007; 11: 882-6. 


\section{Key Messages}

Implications for policy makers

- Involving private sector in tuberculosis (TB) program is necessary due to high volume of private physicians practicing in Iran.

- As quality of data is very important in strengthening TB program performance, knowledge of $\mathrm{TB}$ coordinates should be improved.

- The presence of the concurrently high HIV prevalence can be an alarm for policy-makers; as someone with HIV infection is much more likely to develop TB disease than someone without HIV infection.

- In the region under study, contrary to country's average, the incidence of TB is increasing. This calls for future studies to identify factors associated with TB occurrence.

\section{Implications for public}

The results of our study showed that the incidence of tuberculosis is increasing. Therefore, there is a need for health education to inform public about the factors associated with TB disease including overcrowding, lack of knowledge, poverty, co-infection with HIV, and so on. Moreover, tuberculosis co-infection with HIV is one of the preventable causes of death. Accordingly, improving public awareness of HIV risk is urgently needed. 